This is the accepted version of the forthcoming article: 'Wittgenstein and the Animal Origins of Linguistic Communication', available in final form at DOI: 10.1111/phin.12150. This article may be used for noncommercial purposes in accordance with Wiley Terms and Conditions for Self-Archiving. Any citations should refer to the published version.

\title{
Wittgenstein and the Animal Origins of Linguistic Communication
}

\author{
L.K.K. Cash
}

\begin{abstract}
:
Wittgenstein's notorious sample of a 'complete primitive language' (vi₹: the builders' game of the Philosophical Investigations) is often thought to be closer in kind to animal forms of communication than human language. Indeed, it has been criticised on precisely these grounds. But such debates make little sense if we take seriously Wittgenstein's idea that language is a family resemblance concept. So, rather than argue that the builders' game 'really is a language' (or not), I propose to turn the debate on its head and welcome the comparison. By changing our perspective in this way, I suggest that we can see that the learning of language is crucially dependent upon forms of communication that are animal in nature. I then discuss how these lessons might shed light on empirical research into both the ontogenetic and phylogenetic origins of linguistic communication.
\end{abstract}

$₫ 1$

Animals occupy an interesting place in Wittgenstein's philosophy. On the one hand, we are told that we can imagine a frightened, sad, angry or startled animal, but not a hopeful one; "Can only those hope who can talk?", he asks; "Only those who have mastered a language. That is, the manifestations of hope are modes in this complicated form of life." Elsewhere he remarks that a dog cannot simulate pain, before joking: "Is it too honest?"2 In yet other places Wittgenstein argues that it is partly constitutive of what we call 'thinking' that we do not ask whether fish can think. "The question", he stresses, "is not raised."3

Claims such as these seem to emphasise important discontinuities between human and animal life; but there are other passages that give voice to just the opposite kind of concern. In On Certainty,

1 (2009b: \$1)

2 (2009a: \250; henceforth PI)

3 (1987: \$117; henceforth Z) 
for example, Wittgenstein tells us that he wants to “... regard man here as an animal; as a primitive being to which one grants instinct to but not ratiocination. As a creature in a primitive state. Any logic good enough for a primitive means of communication need no apology from us. Language did not arise out of some kind of ratiocination." ${ }^{4}$ And in other places he discusses Wolfgang Köhler's attempts to prove that chimpanzees can think, expressing agreement that these are indeed examples of cognition, albeit in a primitive form. ${ }^{5}$

My concern is primarily with this second strand in Wittgenstein's thought. In particular, I am interested in the implications that a proper understanding of it has for debates regarding the origins of language. Here the difficulty is that, on the one hand, human beings are seen to be the product of natural selection, thus related in fundamentally important respects to our non-human biological ancestors. And yet, as Chomsky is wont to point out, "[t]here does not seem to be anything homologous (that is, biologically related) or even analogous... [to language] in other related species... The language faculty appears to be biologically isolated in a curious and unexpected sense.",

The problem is not limited to the Chomskyan paradigm. Even those that reject the conception of language as a primarily biological phenomenon nevertheless see a categorical divide between human and animal forms of communication. Michael Tomasello, for example, contends that, "[whereas] animal signals are aimed at the behavior and motivational states of others, $[\ldots]$ human symbols are aimed at the attentional and mental states of others. It is this mental dimension that gives linguistic symbols their unparalleled communicative power, enabling them to be used to refer to and to predicate all kinds of diverse perspectives on objects, events, and situations in the world."7 On this view, even the baby utterances 'more-juice' and 'doggie gone' differ in fundamental respects from the communicative structures of non-human animals — at least as they exist in the wild. ${ }^{8}$

In what follows I am going to try to go some way towards dissolving the appearance of incommensurability. Using Wittgenstein's notorious sample of a 'complete primitive language' (viz: the builders' game of the Philosophical Investigations), I argue that the learning of language is crucially dependent upon communicative forms that have much in common with those found in other species. To this end, I begin by describing three systems of animal communication with which we can draw

4 (1972: \475); Cf. (Z \391)

5 See, e.g., (1980a: \$561) and (1980b: \$\$224-5)

$6(2001: 4)$

7 (2003: 8)

8 I am here bracketing debates over the abilities of animals raised in captivity and trained in rudimentary linguistic skills. See, e.g., Savage-Rumbaugh et al (1993); Cf. Corballis (2011). Though the issues raised by the results of such studies are immensely interesting, they are also controversial and I shall not discuss them further. 
comparison ( $\$ 2)$. I then suggest that many of the common features shared by these systems are also present in Wittgenstein's builders, and detail two objections that have been levelled at the example on precisely these grounds ( $(3)$. I proceed to outline a reading of these passages according to which the objections miss its central point, namely, the foundational role that instruction plays in a child's enculturation into language (\$S4-5). Drawing on work by Danièle Moyal-Sharrock and others, I argue that the example disarms certain conceptual challenges to the very idea of language acquisition (\$6), before discussing how lessons drawn from the builders may shed light on empirical work on language's phylogenetic origins $(\$ 7)$. I bring the discussion to a close with some concluding remarks (\$8).

Honeybees do not speak; but they do, like us, communicate. Through a form of dance, worker bees intimate vital information about the whereabouts of potential resources to the hive. Though the information that is conveyed is relatively simple, the efficacy of their system of communication requires that both distance and direction be discernible from the signals that the bees give. But honeybees do not point, nor do they make use of an abstract notion of number. Rather, the bee dance has evolved in such a way that the distance to the location is correlated with the length of the dance, the direction of the resource indicated by the angle of the dance relative to the sun. ${ }^{9}$

Like honeybees, black-capped chickadees communicate with one another, though not through dance. Rather, they make use of vocalisations both to attract mates and to transmit predator information amongst the flock. In the latter context, the information that is conveyed is surprisingly diverse. For instance, the presence of specific acoustic features (frequency, call duration, etc.) is directly related to the level of threat posed by the predator. Thus, a pygmy owl (high threat) elicits twice as many 'chick-a-dee' calls as does a great grey owl (low threat), and in response to each, a proportionate level of mobbing behaviour occurs. Similarly, different kinds of calls are elicited in response to contrasting situations. So, for example, the chickadees will sing a 'seet' alarm call in response to a flying raptor, while producing a 'chick-a-dee' mobbing call in response to the same predator in a different context. The respective responses (flight or fight) being more or less appropriate to the situation faced. ${ }^{10}$

Though honeybees could hardly be more distant in relation to human beings, and chickadees only marginally closer, the calls of our far more intimate relative, the vervet monkey, are not

9 The example is drawn from Cadena (2011).

10 The example is drawn from Templeton et al (2005). 
significantly more complex. Like the honeybee, vervets make use of signals to convey information useful to the survival of the troop; in this case, they alert one another to the presence of their most common predators by means of acoustically distinct vocalisations. ${ }^{11}$ And, like the chickadee, the behavioural reactions to these alarm calls are highly specialised. For example, upon hearing the bark associated with the presence of a leopard, vervets typically run into nearby trees where they cannot be reached. By contrast, the 'rraup' call produced in response to martial eagles results in a different reaction, namely, that of leaving the trees and running into the thick bush. ${ }^{12}$

Examples such as these are not novel. Indeed, primitive forms of animal communication have been recognised at least since the time of Aristotle. ${ }^{13}$ What is usually denied, however, is that such forms are analogous, let alone equivalent, to language. But why? Is there an essential difference between these primitive systems and mature human languages?

Here one might point to the fact that the English calls are elliptical sentences and can therefore express thought in a way that the chickadee calls (e.g.) cannot. For, what I mean when I say 'Run!' is really: 'You should run'. But this sentence has a syntactic structure that the chickadee vocalisations lack. After all, simply repeating a call hardly qualifies as constructing a sentence, even if subtle differences in frequency, interval gap and duration are admitted as affecting the information conveyed. But since sentences are the basic medium of meaning in any language, ${ }^{14}$ the chickadee calls cannot be genuinely linguistic. Furthermore, if one were to argue that the structure is hidden, lying in the thoughts behind their vocalisations, it would be quite remarkable that the chickadees could not say, e.g., 'Do not run!'. That is, if their thought was the same as ours in this context, we would expect specific logical features to appear in their systems of communication (such as negation) - but they do not.

Not only do these signals seemingly fail to express thought, they also differ from human language in so far as they are not aimed at influencing the thought of others. For human communicators (at least according to a prominent view) use language to influence one another, not directly, but indirectly by calling the listener's attention to objects in the world. Accordingly, communication by means of language involves a complex triadic relationship between speaker, listener and outside referent in which interactions have the structure: ' $\mathrm{I}$ intend for you to share attention

\footnotetext{
11 Seyfarth et al (1980)

${ }^{12}$ It is worth noting that the animals were also tested using recordings of the calls given in the absence of the predatory threat. Because the results remained consistent, the behaviour cannot be explained without reference to the calls themselves. See (ibid).

${ }^{13}$ See, e.g., his remarks in On the Parts of Animals (1961: 660a35-b2).

14 One way to reach this conclusion would be to accept a strong version of Frege's context principle to the effect that words have meaning only in the context of a sentence. Cf. Frege (1953: xxii).
} 
on/about X'. For example, when a human calls out 'Leopard!', the primary intention is to change another's belief state about the presence of danger in the environment, thus allowing the receiver to make a decision about how to react. By contrast, vervet vocalisations (e.g.) seem to lack any such sophistication. They will keep producing their alarm calls in response to a predator even if the rest of the troop is clearly present, looking at the source of danger, and making the same calls themselves. According to Tomasello, this shows that " $[\mathrm{t}]$ heir goal in such situations cannot be to inform others [i.e. to change their mental state], as everyone is clearly already in the know. Whatever they are doing, it is for their own, or their kin's, direct benefit."15

These objections have to do with the content — or lack thereof — of the animal signals. A separate concern arises out of the context of their production. For the use of these signals, again unlike their English counterparts, is restricted to highly specific situations. Chickadees (e.g.) do not use them creatively — in play or jest — but only to warn one another of varying degrees of danger. By contrast, the use of human words is diverse. We use calls such as 'Run!' to warn one another about imminent danger, but also to play games with our children, to scare our friends, and to train soldiers. One can expect to hear such a call at a sporting event, a child's birthday party, or a haunted house — not just when confronted with a dangerous predator. And although one might expect such a call (in the sense that hearing it would not be surprising), the use of human expressions is hardly predictable: there is nothing untoward in the idea that such utterances might not be made in the same context.

Finally, the use of our words is open-ended; there is no limit, set once and for all, to the potential range of our expressions. This has two aspects. First, because most (if not all) human languages possess a grammatical structure that allows one well-formed sentence to be embedded within another, it follows that we can both produce and understand a potentially infinite set of sentences, many of which will never have been heard before. ${ }^{16}$ Secondly, although there are rules for the correct use of our expressions, the ability to intentionally transgress them is as important a feature of our linguistic practices as the rules themselves. "Words without a future — words which contain no possibility for their users of playful, creative repetition, of projection into new contexts," Stephen Mulhall writes, “- are not obviously words at all."17

\footnotetext{
15 (2008: 82)

16 Hauser et al (2002) argue that the recursive nature of grammar is the feature of human language that separates it from animal forms of communication. Cf. Everett (2005b) and Savage-Rumbaugh et al (1993).

17 (2001: 56)
} 
But here we should pause. For, the issues that I have raised in regards to our examples of animal communication ought to engender unease in anyone familiar with the opening sections of the Philosophical Investigations. Indeed, there is an uncanny resemblance between these cases and the example that Wittgenstein himself gives of a 'complete primitive language'.

\section{$\$ 3$}

The Philosophical Investigations begins by introducing us to a 'picture of the essence of human language'. This picture is given to us through St. Augustine's seemingly commonplace reflections upon his introduction to words. Simplifying somewhat, the reflections suggest the following theses: i) words are names (sentences are concatenations of names); ii) the meaning of a word is the object that it refers to; and iii) ostensive definition is the primary form of language acquisition. ${ }^{18}$

Wittgenstein says that this idea of the way that language functions is primitive. But one could also say, he suggests, "that it is the idea of a language more primitive than ours." ${ }^{19}$ We are then invited to conceive of what such a language might amount to:

The language is meant to serve for communication between a builder $\mathrm{A}$ and an assistant $\mathrm{B}$. A is building with building stones: there are blocks, pillars, slabs and beams. B has to pass him the stones and to do so in the order in which A needs them. For this purpose they make use of a language consisting of the words "block", "pillar", "slab", "beam". A calls them out; B brings the stone which he has learnt to bring at such-and-such a call. — Conceive of this as a complete primitive language. ${ }^{20}$

What is both disconcerting and highly relevant for our purposes is that the most intuitive reasons for disqualifying the systems of animal communication as constituting genuine languages are equally applicable to Wittgenstein's own example. There is no syntax for the builders' calls, for there are no sentences; ${ }^{21}$ the function of the vocalisations is to affect action, not thought; ${ }^{22}$ and, finally, their words are used in the performance of these activities, diverse contexts of use seemingly ruled out by fiat. So something is clearly awry, either with the criticisms or with Wittgenstein's assessment of what he has described. Yet there is an important ambiguity of purpose that ought to be respected from the outset. For, just how deliberate is the resemblance between the builders' game and such animal

\footnotetext{
18 For more on the commitments of the Augustinian view, see Baker and Hacker (2005: 43-92).

19 (PI $\int 2$ [my emphasis])

20 (PI $\int 2$ )

21 At least, not in the sense that a sentence is made up of words.

${ }^{22}$ Cf. (PI \$6)
} 
communication systems? And if it is intentional, why does Wittgenstein invite us to conceive of it as a language, something whose possession he will go on to deny, albeit tentatively, to animals? ${ }^{23}$ Some who have rejected the builders' game as constituting a language have taken this to be precisely the point - that in trying to conceive of this case as a language, we inevitably fail.

Supporting this reading is the ability to interpret the builders' game, not as a complete primitive language, but as a subset of our own; as the shorthand employed on a noisy building site for instance. ${ }^{24}$ Because it is possible to make sense of the builders' utterances by juxtaposing the example against a background of a complicated form of life, we assume that it is likewise possible to imagine it as a constituting the entire communication system of a tribe. But now there are doubts about whether what we are describing is of the same kind (i.e., a form of human language). Are their words still names? Unlike what we normally take a name to be, these calls cannot be used in the absence of their bearer. ${ }^{25}$ Are the builders still people? They seem to be more like cavemen, plodding along with their task, faces blank, devoid of all emotion. As articulated by Warren Goldfarb, the purpose of the example is thus to show us that our reluctance to treating the builders as fully human and their calls as genuinely linguistic derives from "...the abrogation of the rest of language. This shows that our everyday applications of these notions presuppose the surroundings provided by the rest of language... When the surroundings are removed, the notions no longer operate quite rightly." ${ }^{26}$

On Goldfarb's reading, then, Wittgenstein's suggestion that we conceive of the builders as employing a complete language is purposefully misleading since it presupposes that we can ignore the holistic framework — the 'rest of language' — that gives our words their meaning. The uncanny effect that the example is then meant to play on our imaginations is accordingly supposed to lead us to recognise the impossibility of taking language piecemeal, of divorcing it from its weave with the rest of our linguistic practices.

But the example can also be read much more straightforwardly, if not un-problematically. Indeed, part of the appeal of Goldfarb's interpretation is that if we do take Wittgenstein at his word, then he is surely wrong to describe the builders' game as a language. Rush Rhees, for instance, offers several reasons for rejecting the example as genuinely linguistic. His chief concern, however, is that for them there is no difference between 'that is not what we normally do' and 'that makes no sense. ${ }^{27}$

\footnotetext{
23 (PI $\$ 25)$

${ }^{24}$ This suggestion is Cavell's (1996).

25 (PI \45)

26 (1983: 272)

27 (1960: 178)
} 
This is problematic because, whereas an arrangement of stones never seen before might be regarded as ugly and thereafter forbidden, such new arrangements are not meaningless. "Unless there were a difference between learning to move stones in the ways people always do, and learning what makes sense, then I do not think we could say they were learning to speak." 28

What would be needed, Rhees suggests, is a richer communicative context — one in which the words of the builders (the dance of the honeybee, the vocalisations of the chickadee, the warning calls of the vervets) hung together with others; one in which, "[...]it makes sense for me to ask you what you mean, to try to get you to say more clearly what you want, and to ask you questions about it: just as truly as it makes sense for me to answer you. The example of the builders does not seem to allow for any of these. Neither could reply to the other [.]"29

What started out as a worry about context (about the lack of diversity in the uses of the builders' calls, about the absence of normative standards needed to distinguish between sense and nonsense) has led straight into a worry about content. Speaking a language, it is now claimed, requires that the participants be able to articulate what it is that they mean, to be able to ask questions and to answer them. But being able to do such things presupposes that things can be asked, denied, said to be thus and so, and so on; this, however, requires a highly complex logico-grammatical structure, one in which assertions, questions, orders, denials, etc., can be distinguished. ${ }^{30}$

Faced with these challenges, there are several courses that one might pursue. The first would be to accept them, thus rejecting Wittgenstein's assessment of his example and, perhaps, its import. Another would likewise be to accept them, but to argue — as Goldfarb does — that this is intentional on Wittgenstein's part: that it is part of his therapeutic method of getting us to indulge our imaginations only to show us that we cannot really conceive of what we originally intended. But however valuable these responses may be in highlighting distinctive features of our own lives with language, it seems to me that both fail to appreciate the weight of Wittgenstein's insistence that language is a family resemblance concept. For, the central point of sections $\iint 66 \mathrm{ff}$. of the Philosophical Investigations is surely (and rightly) that our notion of a language is constituted by nothing other than a network of similarities that overlap and crisscross in interesting ways. Some of these features are present in the builders, while the others that we may have anticipated are not. But it is only for

\footnotetext{
28 Rhees (1960: 178)

29 (Ibid: 182-183)

30 Robert Brandom (2000) makes a similar objection. For discussion see and cf. Williams (2011: 45-52).
} 
someone with a preconceived conception of what language must be like that any of these features will count as essential. ${ }^{31}$

Even more importantly than this, however, is the fact that both readings fail to do justice to two aspects of Wittgenstein's example. The first is the positive role that it plays in the Investigations. As I will argue below, the builders' game serves to highlight the foundational role that such simple practices play in a child's enculturation into language. But in order to get clear about this first neglected aspect, we must examine the second: Wittgenstein's own response to the objections, both in the Investigations and elsewhere.

\section{$\int 4$}

The considerations against counting the builders' game and our examples of animal communication as genuinely linguistic have to do with their primitiveness: firstly, in the lives of the participants, and again in the structure — or lack thereof — of the communication itself. Anticipating the general theme of these objections, Wittgenstein asks, "what is the word 'primitive' meant to say here? Presumably that this sort of behaviour is pre-linguistic: that a language-game is based on it, that it is a prototype of a way of thinking and not the result of thought." ${ }^{32}$ Elsewhere, and specifically in relation to the builders, Wittgenstein's interlocutor complains, "You are just tacitly assuming that these people think; that they are like people as we know them in that respect...", to which he receives the reply: "But the important thing is that their language, and their thinking too, may be rudimentary, that there is such a thing as 'primitive thinking' which is to be described via primitive behaviour." 33

These remarks suggest the following two points. First, the primitive modes of communication that the builders embody are not the product, but rather the root of thought, and, second, there is no sharp distinction between such primitive roots and their extensions - that is, between rudimentary and complex forms of language, thought, and life. ${ }^{34}$ The important question, then, is not whether the builders possess a language or are capable of thought simpliciter, but rather: In what ways is what they do akin to the employment of our languages, and how does it differ? Which features do such communication systems lack, the possession of which we deem to be so important to our own, and

\footnotetext{
${ }^{31}$ Cf. Mulhall (2001: 55). Thanks to Tim Button for pressing me on this point.

$32(\mathrm{Z} \ 541)$

$33(Z\lceil 99)$

${ }^{34}$ Cf. also (Z \129): “We don’t say of a table and a chair: 'Now they are thinking,' nor 'Now they are not thinking,' nor yet 'They never think'; nor do we say it of plants either, nor of fishes; [...] And there is obviously a gradual transition to the case of buman beings." [My italics]
} 
what follows from their absence? Though the preceding discussion has given us several candidate features, I am going focus on two in particular.

Recall that the first complaint that we considered in regards to animal signals centred on their lack of syntactic structure. The fact that they could not form sentences seemed to rule out the possibility that they could be genuinely linguistic. Wittgenstein anticipates a similar objection to the builders: 'Is the call 'Slab!' in example (2) a sentence or a word? - If a word, surely it has not the same meaning as the like-sounding word of our ordinary language, for in $\$ 2$ it is a call. But if a sentence, it is surely not the elliptical sentence 'Slab!' of our language." 35

Wittgenstein is here asking if the builders' call can be said to be equivalent to either (a) the English word 'slab', or (b) the elliptical English sentence 'Slab!'. Our word refers to a type of object - it does not order an action to be performed, as the builder's call surely does. So the call cannot be equivalent to (a). Is it, then, the like-sounding 'Slab!' of English? It seemingly cannot be. For, what our elliptical sentence means (vir. 'Bring me a slab') is not a sentence in the builders' language. But since their call is not short for the longer sentence, how can it mean the same as ours? And if it does not, what sense could it possibly have other than 'Bring me a slab'? We are in a muddle.

This chain of reasoning starts with commonplaces but ends in confusion. The hidden premise is, of course, that the sense of the shorter sentence is dependent on the longer one; that the four-word sentence is logically prior to the elliptical one. If this were so, our ability to mean 'Bring me a slab', would presuppose the syntactic resources capable of generating such a sentence (and now the question of where these resources come from becomes significant). Language cannot, so to speak, come piece by piece. $^{36}$

Wittgenstein aims to cut off these inferences before they can get started. For how has it come about that the dependence of the elliptical sentence on its extension runs that way? "Why", Wittgenstein asks, “shouldn't I conversely have called the sentence 'Bring me a slab' a lengthening of the sentence 'Slab!?’”77 Well, comes the reply, because our call 'Slab!' really means 'Bring me a slab'. - This is of course true, but empty. We say that 'A' means ' $\mathrm{B}$ ' when there is some confusion about what 'A' means. And though we do not say “ 'Bring me a slab' means 'Slab!'”, this is simply because

\footnotetext{
35 (PI \$19)

${ }^{36}$ Cf. Chomsky's remarks about the evolution of language: “...it is almost as if there was some higher primate wandering around a long time ago and some random mutation took place, maybe after some strange cosmic ray shower, and it reorganized the brain, implanting a language organ in an otherwise primate brain. That is a story, not to be taken literally. But it may be closer to reality than many other fairy tales that are told about evolutionary processes, including language." (2001: 4) 37 (PI \$19)
} 
it is difficult to imagine a situation in which the latter would clarify the former to someone who did not understand it.

But this does not satisfy the interlocutor who seizes upon this very point: the shorter sentence cannot clarify the longer sentence precisely because the latter captures the full sense (the proposition, the thought in its entirety, or some such thing). For, “... when I call out 'Slab!', then what I want is that he should bring me a slab." 38 Again, Wittgenstein concedes the point but questions its import. For what does 'wanting this' consist in? It certainly does not involve thinking of another sentence from the one that you utter while you utter it. Rather, we say that our elliptical sentence means 'Bring me a slab' in order to contrast it with other sentences of our language - e.g. 'Bring her a slab', 'Bring me five slabs', 'Throw me a slab'. We express the meaning of the elliptical sentence by means of the longer one in order to forestall potential misunderstandings — the fact that the builders' language lacks such verbal forms simply means that it cannot be so contrasted. It does not follow from this that their call cannot mean the same thing. Rather, Wittgenstein suggests that meaning the same, having the same sense, etc., consists in the expressions in question having the same use. And as to whether the builders' call is a word or a sentence, you can call it one, the other, or both; nothing substantial rides on this and the question is liable to obscure the function that the expression is being put to.

Does the builder's call, then, have the same use as our elliptical sentence? It is central to my understanding of Wittgenstein's purpose in these remarks that the answer is yes, it can — indeed, that in the appropriate surroundings, “...it is our 'elliptical' sentence." 39 This point is often missed because the use that our word 'slab' is put to is obviously far more expansive than it is in the builders' language. ${ }^{40}$ But, first, Wittgenstein is not talking about a word per se, but the employment of a call — that is, of an expression that is already in use (rather than a sign idling). And second, what characterises the call and our elliptical sentence as commands to bring a slab, is the role that these expressions play in the context in which they are employed. Of course this involves an appreciation of the surrounding circumstances

\footnotetext{
38 (PI $\left.\int 19\right)$

39 (PI $\int 19$ [my emphasis])

40 Thus, Nancy Baker contends that " $[\mathrm{t}]$ he answer is no, because in addition to context and matching up the right word with the right object, a large part of what determines a word's meaning or makes a concept what it is are its connections to other words, perhaps even to the rest of language." (2012: 62) Note the explicit reference to words. And now compare what Wittgenstein himself says in the Brown Book: "Objection: the word 'brick' [...] has not the meaning which it has in our language. - This is true if it means that in our language there are usages of the word 'brick' different from our usages of this word in [the builders' game]. But don't we sometimes use the word 'brick!' in just this way? (1969: 77-78 [second emphasis mine])
} 
insofar as these affect an expression's functioning; but in both the builders' game and the shorthand of a construction site (say), the use is exactly the same.

The lesson, then, is not that the builders' game really is a language (this, Wittgenstein would have thought, is a wrong question); rather, it is that the absence of syntax in this context does not, in itself, infringe upon their ability to use 'Slab!' to mean 'Bring me a slab'. What does have to be given up, though, is the idea that their calls are names of objects. For what the builders clearly cannot do is make use of 'Slab!' in a referential role; that is, as a word to talk about an object (or type of object). They can only order an action to be performed and, what is more, can only do so in the presence of the object itself. Unlike a name, the paradigmatic use of which is to refer in the absence of its bearer, the builders' calls are bound up inextricably with their objects.

Thus, on the reading here outlined Wittgenstein's suggestion that we conceive of the builders' game as an example of a 'complete primitive language for which Augustine's description is right' is indeed treacherous. But, and this needs emphasising, it is so in a way unlike that described by Goldfarb. The point of exercising our imaginations in this case is not for us to see that what we are imagining is no longer a language, but rather that it is not a case for which Augustine's description is right.

Nevertheless, the builders seemingly lack the capacity to explain what it is that they mean and, perhaps also, a distinction between sense and nonsense. And this leads to the second objection that I wish to consider. For could one not protest along the lines outlined by Rhees that the lack of a distinction between 'that is not what we normally do' and 'that is senseless' rules out the possibility that they can accurately be described as speaking?

The worry Rhees seems to have is that the lack of such a distinction blurs an essential difference between human and animal forms of communication. "What they have learned," he strikingly remarks, "are signals which cannot be used in any other way." 41 Though it is unclear precisely what Rhees means by 'signal', it must be, I think, closely related to the communicative structures of non-human animals. And we have certainly agreed that the use of these calls does not come close to approaching the multiplicity of our words. But there is still a gap here, for what is the connection between the ability to use a word in multifarious ways and the possibility of nonsense? Why does the latter presuppose the former?

41 (1960: 177) 
The relationship that Rhees sees lies in the fact that our words have standards of correct use - rules that determine which of a word's combinatorial possibilities are right, which are wrong. "[These] come in", he says, "when we say [that someone] is not using the word in the same way now, or when we say someone has misunderstood." ${ }^{2}$ The point is that it is only through a violation of these standards (what Wittgenstein called 'grammar') that nonsense results. "But", writes Rhees, "I do not see how there can be any such standard in the game Wittgenstein has described." 43

There is something important in this. Speaking is a normative activity and, as such, is subject to correction, instruction, praise and blame. This comes out, as Rhees says, when we say that someone has misspoken or that they fail to understand the meaning of a word. But such activities only make sense, he thinks, against a background in which we make use of explicit standards of correctness, that is, of rules - the paradigmatic example of which is an explanation of meaning as would be given to someone who does not understand a word (or sentence). But since the builders cannot explain what they mean in this way, there is no difference between misspeaking and doing something out of the ordinary. And this is why, for Rhees, the possibility of nonsense is essential to human language.

But this is an over-intellectualisation of nonsense, normativity, and, indeed, language. In the first place, Rhees's claim that there is no distinction in the builders' game between 'that is not what we normally do' and 'that makes no sense' should be rejected. For one may grant that there is a difference between learning how to arrange stones and learning to speak, but deny that these are left un-differentiated in the example. After all, the builders do not use arrangements of stones to communicate, whereas they do make use of their calls in this way. So, suppose that one builder calls out 'gavagi', pointing indiscriminately at slabs, beams, and pillars, while the second builder watches, bemused. The first then appears frustrated and repeats her call. Can we not then say that she is trying to say something to her helper, but failing to make sense? If so, similar scenarios are conceivable in the case of the vervets, chickadees, and bees.

Secondly, it is true that the builders cannot explain what they mean if all this amounts to is that they cannot say such things as 'When I say 'slab' you are to pick up that object and bring it to me'. But what Rhees ignores is the fact that the builders are capable of instructing one another in the use of their words. Not, of course, by reference to more of them, but rather in deed. Let me explain.

\footnotetext{
42 (Ibid: 179$)$

43 (Ibid: 179)
} 
What I have in mind is a form of instruction, and therewith normativity, that is embodied. Consider the difference between these two kinds of teaching:

(1) A says to B: 'When I say 'slab' you are to pick up that ( object and bring it to me. Ok, slab'. - B picks up a beam and brings it to A. - 'No, that is a beam.' - B picks up a slab and brings it to A. — 'Yes, that's right.'

(2) A says to B: 'Slab' and points at a slab. B picks up a beam and brings it to A. A slaps B on the wrist and points again at the slab. B brings a Slab. A pats B on the back.

In (1) the teaching is done via (what Rhees calls) explanation. It is effective only because both A and $\mathrm{B}$ have a considerable linguistic repertoire, one far greater than that afforded to the builders. Here the rule, 'if X says 'slab' you are to bring a slab to X', functions as a standard of correctness and B, once she understands it, can use it to guide her future actions. This is the kind of normativity that Rhees has in mind above. But since this is obviously not possible for the builders, their form of instruction must, I think, look more like (2). This is why Wittgenstein is quick to distinguish the kind of instruction that is available to them from more advanced forms:

[They] are brought up to perform these actions, to use these words as they do so, and to react in this way to the words of others.

An important part of the training will consist in the teacher's pointing to the objects, directing the child's attention to them, and at the same time uttering a word; for instance, the word 'slab' as he displays that shape. (I do not want to call this 'ostensive explanation' or 'definition', because the child cannot as yet ask what the name is... $)^{44}$

What makes the activity normative is the way the child's behaviour becomes constrained: it is shaped within the pedagogical context to conform to the directives of the teacher. ${ }^{45}$ But since the teacher is not capable of citing further words to explain what to do (since the child would not understand them), the normativity will be based primarily around reward and punishment. Crucially, however, the child need not intellectualise the fact that she has done something wrong. She does not need to think about what the slap 'means', but can simply react naturally — in much the same way, in fact, as an animal might. Wittgenstein writes: "I am using the word 'trained' in a way strictly analogous to that in which we talk of an animal being trained to do certain things. It is done by means of example,

\footnotetext{
44 (PI §6)

${ }^{45}$ Cf. Williams (2012: 377-378). Of course, the builders' children might learn the calls in another way (through imitation, e.g.); but the important point is that they could be corrected.
} 
reward, punishment, and suchlike." 46 The immensely significant point in all of this is that it is through such training that the child may come to understand the meaning of the call. This is normativity, instruction, and understanding in their most primitive forms.

We are now in a position to see the positive role that the example is meant to play in the Investigations. As I argued in the preceding section, the example has the negative conclusion that, even in the simplest of cases, Augustine's description fails. But Wittgenstein also uses it to set up the important relationship between these rudimentary activities that "A child uses [...] when he learns to talk", ${ }^{47}$ and the more complicated forms of language that characterise our lives. For, while Rhees is right that in such simple contexts there is no such thing as explaining the meaning of a word (in the technical sense canvassed above), he does not seem to realise that the capacity to ask for the meaning of a word, the ability to explain what one means with other words, etc., is dependent upon the primitive forms of learning that are available to the builders. Wittgenstein's argument is that, rather than constituting the fundamental form of language acquisition (as Augustine's description suggests), ostensive explanation (or definition) presupposes that the initiate understand the general role of the word in the language-game (i.e. whether it is a colour word, number word, etc.). Ostensive explanation, he suggests, "is [...] a language game in its own right." ${ }^{48}$ Indeed, it is one of the most important. But then it cannot be learned in the same way, on pain of regress. ${ }^{49}$ It is built, rather, upon the kinds of primitive communicative contexts that lie at the foundation of our languages (of which the builders' game is but one example).

These points suggest a picture of the ontogenetic origins of linguistic communication that runs contrary to claims that you must know a language in order to learn one. ${ }^{50}$ For if what has been said up to now is on point, the kinds of language games that the builders embody demonstrate the possibility of acquiring primitive linguistic skills through forms of instruction that do not presuppose the linguistic competence of the initiate learner.

\footnotetext{
46 (1969: 77)

47 (PI $\left.\int 5\right)$

48 (PI $\int 27$ )

49 For an elaboration of the argument, see Medina (2002: 165-173).

50 The reference is, of course, to Fodor (1975: 63-64). But also see and cf. Chomsky (1965: 25).
} 
The objection that is likely to arise at this stage, however, is that even if it is admitted that such forms of training serve to initiate a child into language, it is nevertheless opaque how one can move from such primitive reactions to fully intentional speech. Rhees writes:

If you see someone who has been knocked down, and see that his leg is giving him great pain, you may call to him, ask him, and ask other people who come along [...]; also: if you saw that I had seen the man knocked down and that I could see that his leg was hurting him terribly, and that I just [...] started to walk on, you might say: 'Wait a minute! Can’t you see he’s hurt? You can’t just leave him here.' [...] How would this behaviour 'emerge' from the instinctive behaviour in an animal?51

I am not entirely sure what Rhees is asking for. If the question is the empirical one about the ways in which children do in fact learn such uses of language, then I am not qualified to answer it. Others, however, have gone some way towards doing so in a manner entirely consistent with what has been said up to now. ${ }^{52}$ If, on the other hand, it is meant to amount to a philosophical challenge - to imply that there is some sort of incoherence in the suggestion that such forms of speech might emerge from instinctive reactions - then Wittgenstein himself provides an answer:

$[\mathrm{H}]$ ow does a human being learn the meaning of the names of sensations? - of the word 'pain' for example. Here is one possibility: words are connected with the primitive, the natural, expressions of the sensation and used in their place. A child has hurt himself and he cries; and then adults talk to him and teach him exclamations and, later, sentences. They teach the child new pain-behaviour. ${ }^{53}$

He also suggests that similar things could be said in response to the question 'How is the connection between name and thing named set up?' And this, I take it, is similar again to the question of how the triadic relation between speaker, listener, and outside referent - the relation characteristic of many mature uses of language - develops. Let us flesh this idea out with a snapshot of what such a developmental trajectory might look like in practice.

i. A child is placed in a high-chair and fed juice. Her juice is then taken away and she cries. 'Do you want more juice?', her father asks, waving the juice box in front of her. She reaches for the juice and he gives her some more. She stops crying.

ii. The same child, now a bit older, is placed in her high-chair and fed juice. When it is taken away she exclaims 'more juice!' Her father gives her more, which she happily accepts.

\footnotetext{
$51(1997: 2)$

52 See Montgomery (2002) for an account inspired by considerations similar to those discussed above.

53 (PI $\$ 244)$
} 
iii. The child, a bit older still, is being carried off to bed. 'More juice!' she exclaims. 'But you've already had juice', her father says. 'More juice!', she repeats. She is then placed in her highchair and given juice. But she does not drink. 'Ok, back off to bed then.' - 'More juice!'

iv. The child is even older now. She is placed in a booster seat and asked 'Are you thirsty?' 'More juice!' - 'Ok, which would you like, pineapple ( or grape ( She points to the grape juice. 'Don’t point', her father says. 'Say: “grape juice”.' - 'Grape juice!' She is given the grape juice. 'Good. This (

This, it seems to me, is a banal description of the sort of interaction that one might expect to observe between a father and his daughter at various points in the latter's ontogeny. At the first stage, the child's behaviour is little more than that of a pup straining for milk, or a chick crying out with hunger; accordingly, its production does not presuppose the psychologically complex communicative intent of mature language users — as Danièle Moyal-Sharrock emphasises, it is spontaneously expressive, not goal directed. ${ }^{54}$ But it is nevertheless a primitive communicative context in which the child makes her feelings known and where, like the builders' calls, 'More juice' becomes associated with its object. In time (so our story assumes) the child will learn to replace her instinctive crying and grasping with words. But even at this second stage, the question of whether or not the communication is fully intentional is left unsettled. There is no need to over-intellectualise the child and hypothesise that her goal in such situations is to direct another's attention to an object. It may be, certainly, and experiments might confirm that it is (e.g. if the child stops making the exclamation when the adult is clearly trying but for some reason failing to get the juice); but it is also possible that the exclamation has simply replaced the crying and that the child will continue to make it so long as her desire remains. A variation of degrees is, I think, imaginable here. Once we reach the third stage, however, the child's behaviour shows the primitive roots of deception: she does not want to go to bed and says 'More juice' in order not to. The natural locutions of goal-directed action are practically unavoidable.

From here the transition to referential uses of speech is again affected, not through theorising on the child's part, but by means of further training. Pace Fodor, a child can come to understand what 'grape juice' means without forming a hypothesis about the extension of the concept grape juice. ${ }^{55}$ How? By observing her father ask 'Do you want grape juice ( or pineapple juice ( in a context in which she is sat at the table, waiting to be fed. The connection between language and the world is made

54 (2010: 296)

55 Cf. Fodor (1975: 63-64) 
through the activity of drinking juice, not by means of theorising about what words mean. And once this connection is firmly established, the ambiguity of ostensive explanation is nullified: the step to naming and, ipso facto, paradigmatically referential uses of language becomes possible.

This is, admittedly, little more than a story; but it is not, I think, an unbelievable or even remarkable one. Moreover, I need not claim that a child's enculturation into language is everywhere like this. Rather, the point of the example is to demonstrate the possibility of coming to language without the resources afforded by its possession. Moyal-Sharrock summarises the general idea well:

[T] he child learns to replace his initial crying for food with intentional gesturing for food, and eventually with more sophisticated $[\ldots]$ requests. The word replaces the gesture and takes over its function. It isn't that the word is now hooked or mapped on to the behaviour, but that it replaces it [...] The infant's primitive crying is not goal-directed, but instinctively expressive; of course the infant will soon learn to 'direct' or stage its crying to serve a purpose, but that is a refinement of the primitive gesture. ${ }^{56}$

If this is right then the intricate uses of language that Rhees discusses, while they may lie much further down a complex developmental road, nevertheless have a clear enough foundation in the instinctive behaviour of the pre-linguistic child.

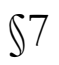

Our discussion began with three examples of animal communication and, before drawing the discussion to a close, I want to briefly comment on the phylogenetic implications of all this. For, although I have been consistently emphasising the similarities between the builders' game and the three examples, the possibility of shaping another's communicative behaviour by means of instruction does I think represent a significant difference. Now, whether it is a difference between human and animal forms of communication generally is, of course, an empirical question and I shall not argue that the evidence is overwhelmingly in favour of it being so. ${ }^{57}$ What I do want to comment on the importance of such a general difference, should that it be.

The significance lies in the potential expansion of the communicative system that the pedagogical context creates. For the capacity to instruct and — no less importantly — to learn from

\footnotetext{
56 (2010: 296)

57 But others have. See Tomasello (1999: 33ff.) and Boesch and Tomasello (1998) for arguments that instruction in non-human animals, if it exists all, is extremely rare.
} 
instruction is bound up with the characteristic way that human cultural practices, including language, accumulate modifications over time. This is often referred to as the 'ratchet effect' since,

$[\ldots]$ a key aspect of the mechanism is that modifications are taken up by others faithfully and continue in faithful replication until still newer modifications come along. This faithful transmission is partly due to the especially powerful skills of social learning employed by human children [...], along with the fact that adults explicitly teach children things as well. ${ }^{58}$

The instructional contexts that the builders embody provide the basis for the cultural ratchet since children learn, not simply how to proceed, but how one ought to proceed in relevantly similar circumstances. That is, instruction instils within the initiate learner a normative attitude towards what is being taught. As Schmidt and his colleagues explain, "Young children [...] not only learn how to perform normatively rule-governed activities from adults, but they already understand them as rule governed and enforce these rules on third parties." ${ }^{59}$ And as Tomasello and Herrmann report,

[...] when adults teach them things, children trust this so much they often jump to normative conclusions. [...] For example, in a recent study, 3-year-old children who witnessed a puppet playing a game in a manner discrepant with the way they had been taught objected strenuously: The puppet was not doing it "right". 60

This makes human children the perfect vessel for the dissemination (and hence preservation) of the innovations and modifications that previous generations have made to the language which they will eventually inherit, and allows them to master complex techniques involving innovations that no single individual could invent (e.g., language). ${ }^{61}$

By contrast, when communicative behaviours are not learnt, or are learnt but without the possibility of instruction, growth in the complexity of the communicative system as a whole is difficult to explain. The reasons for this require little comment in the case of unlearned behaviour: since its development is subject to the selection pressures of the environment, cumulative change happens on timescales orders of magnitude greater than the processes of cultural evolution. But the point is less obvious in regards to behaviour that is learnt outside of the pedagogical context. Why not think that

\footnotetext{
58 Schmidt et al (2011: 530)

59 (Ibid: 531)

60 (2010: 6) For the study itself see Rakoczy, Warneken, \& Tomasello (2008).

61 See and cf. Tomasello et al (1993).
} 
the powerful forms of learning (individual, social, and — arguably — imitative), that many species have access to are equally likely to facilitate the ratchet effect?

Individual learning (stimulus response conditioning, trial and error learning) clearly cannot form the basis for cumulative change across generations without a means of disseminating the skills learnt: there must be some social aspect to the process. But social learning is usually defined simply as individual learning that is in some way influenced by the social environment. ${ }^{62}$ For instance, a young chimp may follow his mother to a termite mound and use the stick she leaves behind to fish out the insects for himself. Here the social context plays an important and active role in the development of the young chimp's skills. Yet while this can and does lead to variations in termite fishing techniques across chimpanzee communities, ${ }^{63}$ it does not result in a more sophisticated practice because the actual learning processes remain individual. Young chimps are not learning from one another's methods or strategies for solving the problem per se, but are rather acquiring it for themselves anew, simply as a result of being placed within the relevant context. Thus, as Richardson and Boyd put the point, "even if an especially talented individual found a way to improve [upon the technique], this innovation would not spread to other members of the group because each individual learned the behaviour anew. Local enhancement is limited by [...] the fact that each new learner must start from scratch."64

For just this reason it is often thought that true imitation is key in facilitating the cultural ratchet. ${ }^{65}$ As typically understood, imitation is the process by means of which the animal learns through direct observation of another's behaviour (including its strategies and consequences) to execute similar behaviours and to achieve the related results. ${ }^{66}$ It is thus easy to see why such a form of learning appears to provide a stable foundation for the maintenance of complex skills across time: if animals are capable of imitating one another, then it seems as if innovations will be copied, mastered, and passed on to future generations. But is imitation enough? It is not at all obvious that it is. The problem is that imitation does not require that the individuals acquire a normative attitude to what they learn: rather than understanding a particular way of doing things as the 'right' one, individuals simply learn that it is a possible means of achieving some end. But if another technique (however acquired) works similarly well, there is nothing to prevent the animal from changing its method. As Heyes points out, this makes skills learnt through imitation liable to modification and erosion as a result of circumstantial

62 (Ibid: 496); see also Bandura (1986) and Heyes (1993).

${ }^{63}$ Luncz and Boesch (2015)

64 (1996: 81)

${ }^{65}$ By, e.g., Tomasello et al (1993).

${ }^{66}$ See, e.g., Heyes (1993: 1000). 
environmental variables. And while this might be beneficial in the short term, it means that what gets passed on is not necessarily a generally improved technique, but simply a different one. It thus seems at least unlikely that imitation on its own could facilitate the cultural ratchet since it fails to insulate the acquired techniques from the other forms of learning available to the animal. ${ }^{67}$

Unsurprisingly, I think, it is precisely this kind of insulation that is fostered by the teaching context. Indeed, I would argue that the transformation of regularities into rules makes little sense except against a background in which instruction plays at least a part. Of course, once the normative foundation is in place, imitative learning can and does play a key role in the faithful transmission of techniques - explicit instruction is not everywhere required. This is an important fact, but one that should not be overemphasised. For, if what has been said up till now is on point and the capacity to initiate children into the mastery of a technique proves to be uniquely human, then not only does Wittgenstein's insistency on the primacy of instruction provide a way of understanding a child's enculturation into language, it also provides a conceptual foundation for much of the theoretical work on its phylogenetic origins.

Human beings are, like every other species, unique. And it is no doubt true that our capacity to use a rich language is part and parcel of that. But claims to the effect that there is nothing analogous to human forms of communication in any other animal species are simply untrue. This is not, I have argued, because animal forms of communication are more complex than we are inclined to think, but rather because human languages rest on a primitive form of communication that is animal in nature.

Under the reading that I have outlined, Wittgenstein's builders embody this primitive form and provide a model for understanding how a child might come to language without the resources afforded by its possession. This, I think, disarms the conceptual challenge about language acquisition posed, in different ways, by Rhees and Fodor: there is no good reason to think that there is anything conceptually problematic in the supposition that a child might develop linguistic skills without already having a language. ${ }^{68}$ Admittedly, I have said nothing about 'poverty of the stimulus' arguments that aim to show, as a matter of fact, that there is an unbridgeable gulf between the linguistic input a child

67 (Ibid: 1004)

${ }^{68}$ I should say that Rhees (1997: 13) explicitly claims to be in agreement with Malcolm's (1982) polemics against the idea that language is, or must be, innate. But it is difficult (for me) to see what alternative is available to him given his own avowed rejection of the notion that language could arise from primitive forms of behavior. 
receives and the linguistic abilities they develop. ${ }^{69}$ But, first, these empirical claims are consistently challenged; they are by no means as well established as they are often made out to be. ${ }^{70}$ Second, there are alternative theories; universal grammar is no longer the only show in town. ${ }^{71}$ And, finally, models which posit a specialised organ to explain the ontogenesis of language - while at the same time denying that there is anything analogous throughout the rest of nature — offer no plausible account of its phylogenetic origins. ${ }^{72}$ To this end I have tried to show how lessons drawn from the builders might be put to use in understanding the cultural evolution of linguistic complexity. These remarks were speculative, but it seems to me that they are at least initially supported by empirical research. ${ }^{73}$

\section{St. John's College, Cambridge}

\section{Works Cited}

Aristotle. (1961). On the Parts of Animals, trans. A. L. Peck. Cambridge, MA: Harvard University Press. Baker, G. P. \& Hacker, P. M. S. (2005). Wittgenstein: Understanding and Meaning. Oxford: Basil Blackwell. Baker, N. (2012). "The Difficulty of Language: Wittgenstein on Animals and Humans." In M. Burley N. Forsberg, \& N. Hamalainen (eds.), Language, Ethics and Animal Life: Wittgenstein and Beyond. New York: Bloomsbury, pp. 45-64.

Bandura, A. (1986). Social Foundations of Thought and Action. New Jersey: Prentice Hall.

Boesch, C. \& Tomasello, M. (1998). Chimpanzee and human culture. Current Anthropology 39: 591-604.

Boyd, R. \& Richerson, P. (1996). "Why Culture is Common but Cultural Evolution is Rare." Proceedings of the British Academy 88: 77-93.

Brandom, R. (2000). Articulating Reasons. Cambridge, MA: Harvard University Press.

Cadena, V. (2011). "Sleepless nights lead to miscommunication in honey bees." Journal of Experimental Biology 214 [pagination not available online].

\footnotetext{
${ }^{69}$ For a classic presentation of the argument, see Chomsky (1986).

${ }^{70}$ In this regard, see Pullum and Scholz (2002) and Everett (2005a). Also see Moyal-Sharrock (forthcoming) for an engagement with the empirical literature from a Wittgensteinian perspective.

${ }^{71}$ Consider, for instance, the theory outlined in Tomasello (2003).

72 On this see Corballis (2011).

73 The preparation of this paper has benefitted tremendously from conversations with Michael Potter, Tim Button, Nadav Matalon, and Danièle Moyal-Sharrock. I am thankful to them and to the benefactors of St John's College, Cambridge, for their support.
} 
Cavell, S. (1996). "Declining Decline: Wittgenstein as a Philosopher of Culture." In S. Mulhall (ed.), The Cavell Reader. Oxford: Blackwell.

Chomsky, N. (1965). Aspects of the Theory of Syntax. Cambridge, MA: MIT Press. (1986). Knowledge of language: its nature, origin, and use. New York: Praeger.

- (2001). The Architecture of Language. New Delhi: Oxford University Press.

Corballis, M. C. (2011). The Recursive Mind. Princeton: Princeton University Press.

Everett, D. (2005a). "Biology \& Language: a Consideration of Alternatives." J. Linguistics 41: 157-175. (2005b). "Cultural Constraints on Grammar and Cognition in Pirahã." Current Anthropology 46(4): 1-69.

Fodor, J. (1975). The Language of Thought. Hassocks: Harvester Press.

Frege, G. (1953). The Foundations of Arithmetic: A Logico-Mathematical Enquiry into the Concept of Number, trans. J. L. Austin. Oxford: Blackwell.

Goldfarb, W. (1983). "I want you to bring me a slab: Remarks on the Opening Sections of the Philosophical Investigations." Synthese, 56(3): 265-282.

Hauser, M., Chomsky, N. \& Fitch, W. T. (2002). "The Language Faculty: What Is It, Who Has It, and How Did It Evolve?" Science 298: 1569-1579.

Heyes, C. M. (1993). "Imitation, Culture and Cognition." Animal Behavior, 46: 999-1010.

Luncz, L. V. \& Boesch, C. (2015). "The Extent of Cultural Variation Between Adjacent Chimpanzee (Pan troglodytes verus) Communities; A Microecological Approach." American Journal of Physical Anthropology 156: 67-75.

Malcolm, N. (1982). "Wittgenstein: The relation of language to instinctive behaviour." Philosophical Investigations 5(1): 3-22.

Medina, J. (2002). The Unity of Wittgenstein's Philosophy. New York: SUNY Press.

Montgomery, D. E. (2002). "Mental Verbs and Semantic Development." Journal of Cognition and Development 3(4): 357-384.

Moyal-Sharrock, D. (2010). "Coming to Language: Wittgenstein's 'Social' Theory of Language Acquisition." In V. Munz, K. Puhl \& J. Wang (eds.), Language and World, Part One: Essays on the Philosophy of Wittgenstein. Berlin: De Gruyter, pp. 291-314.

_ (Forthcoming). "Universal Grammar: Wittgenstein vs Chomsky." In M. A. Peters \& J. Stickney (eds.), A Companion to Wittgenstein on Education: Pedagogical Investigations. Springer (2016).

Mulhall, S. (2001). Inheritance and Originality. Oxford: Clarendon Press. 
Pullum, G. K., \& Scholz, B. C. (2002). "Empirical assessment of stimulus poverty arguments." The Linguistic Review 19: 9-50.

Rakoczy, H., Warneken, F. \& Tomasello, M. (2008). "The sources of normativity: Young Children's awareness of the normative structure of games." Developmental Psychology 44: 875-881.

Rhees, R. (1960). "Wittgenstein's Builders." Proceedings of the Aristotelian Society 60: 171-186. (1997). "Language as Emerging from Instinctive Behaviour." Philosophical Investigations 20(1): $1-14$.

Savage-Rumbaugh, S., Murphy, J., Sevcik, R., Brakke, K., Williams, S., Rumbaugh, D. \& Bates, E. (1993). Language Comprehension in Ape and Child (Vol. 58) Chicago: University of Chicago Press.

Schmidt, M., Rakoczy, H. \& Tomasello, M. (2011). "Young children attribute normativity to novel actions without pedagogy or normative language." Developmental Science 14: 530-539.

Seyfarth, R., Cheney, D. \& Marlor, P. (1980). "Vervet Monkey Alarm Calls: Semantic Communication In A Free-Ranging Primate." Animal Behavior 28: 1070-1094.

Templeton, C., Greene, E. \& Davis, K. (2005). "Allometry of Alarm Calls: Black-Capped Chickadees Encode Information About Predator Size." Science 308 [pagination not available online].

Tomasello, M. (1999). The cultural origins of human cognition. Cambridge, Ma: Harvard University Press. (2003). Constructing a language: a usage-based theory of language acquisition. Cambridge, Ma: Harvard University Press.

- (2008). Origins of human communication. Cambridge, Ma: MIT Press.

Tomasello, M. \& Herrmann, E. (2010). "Ape and human cognition: What's the difference?" Directions in Psychological Research 19: 3-8.

Tomasello, M., Kruger, A. \& Ratner, H. (1993). "Cultural Learning." Behavioral and Brain Sciences 16: 495-552.

Williams, M. (2011). Blind Obedience. London: Routledge. (2012). "The Builders." In W. Löffler and C. Jäger (eds.), Epistemology: contexts, values, disagreement. Berlin: De Gruyter, pp. 371-398.

Wittgenstein, L. (1969). The Blue and Brown books. Oxford: Basil Blackwell. (1972). On certainty, trans. D. Paul \& G. E. M. Anscombe. London: Harper Torchbooks. (1980a). Remarks on the philosophy of psychology Vol.1, trans. G. E. M. Anscombe. Oxford: Blackwell. (1980b). Remarks on the philosophy of psychology Vol.2, trans. G. E. M. Anscombe. Oxford: Blackwell. 
(1987). Zettel, trans. G. E. M. Anscombe. Oxford: Basil Blackwell.

(2009a). Philosophical investigations, trans. G. E. M. Anscombe, P. M. S. Hacker \& J. Schulte, (Rev. 4th ed.). Oxford: Wiley-Blackwell.

(2009b). Philosophy of Psychology: A Fragment, trans. G. E. M. Anscombe, P. M. S. Hacker \& J.

Schulte, (Rev. 4th ed.). Oxford: Wiley-Blackwell. 